\title{
La crítica como intervención política
}

\author{
Sobre Pratt, Mary Louise (2018). \\ Los imaginarios planetarios. \\ Madrid: Aluvión, 2018
}

\section{(1) María Virginia González}

Encontrarnos con un nuevo libro de Mary Louise Pratt nos evoca su ineludible Ojos imperiales. Literatura de viajes y transculturación (1992), publicado por primera vez en nuestro país en 1997 por la Universidad Nacional de Quilmes. Allí, la investigadora canadiense especialista en literaturas comparadas (hoy Profesora Emérita del Departamento de Español y Portugués de NYU) proponía analizar el control del imperialismo sobre la imaginación y el conocimiento de los "otros" en un corpus heterogéneo de libros de viajes de europeos que se habían desplazado por América y África. Para ello, recupera el concepto de "transculturación" de Fernando Ortiz con el objetivo de revisar los sentidos y los usos que los dominados hacen de la cultura dominante. En la última etapa de este libro, que se extiende desde la segunda mitad del siglo XIX hasta mediados del siglo XX, la autora pone en evidencia la readecuación del imaginario imperialista en el contexto del neocolonialismo, caracterizado por la movilidad y la globalización. Podemos leer la continuidad de ese eje en Los imaginarios planetarios, libro editado por Aluvión en 2018, que nuclea los ensayos (la mayoría por primera vez en español) dedicados al estudio de Latinoamérica a través de los imaginarios que construyen esta entidad. Para examinar este objeto tan importante como heterogéneo, Pratt analiza un amplio espectro de formatos de la cultura letrada (novelas, poesías, ensayos, cine), pero incorpora otros objetos de estudio para ampliar el campo del conocimiento estético y cultural; una decisión metodológica coherente con sus trabajos anteriores en los que también considera los bordes de la construcción entre las llamadas cultura alta y cultura popular.

El Prólogo de Los imaginarios planetarios está a cargo de Lina Meruane. En esas páginas de apertura, la colega y discípula de Pratt sintetiza las líneas centrales del libro y hace un reconocimiento a la labor docente de la autora al sostener que sus aportes sobre la revisión del pasado constituyen un modo de comprender y dar sentido al presente. En la Introducción, Pratt anticipa los temas que la interpelan, cuando advierte que su análisis está atravesado por un "parti pris apasionado con las grandes luchas emancipatorias del hemisferio y del planeta: la descolonización, es decir, la lucha por eliminar las persistentes jerarquías e idearios (neo) coloniales: el anticapitalismo, es decir, la lucha contra la explotación de las personas y de la tierra, y el feminismo, es decir, la lucha contra el patriarcado y la dominación heteromasculina, tema particularmente central en la segunda parte" (16-17). Aunque el libro reúne trabajos producidos en diferentes momentos, se percibe que no se trata de un conjunto aleatorio, sino que la selección y el orden responden al interés de organizar dos grandes bloques -Fondo y Figura- de ocho capítulos cada uno.

La primera parte -Fondo- se centra en el análisis de los relatos que han sustentado cierta historia latinoamericana: el Imperio, la República, la Modernidad, la Multiculturalidad y el Neoliberalismo. El primer capítulo puede leerse como la argamasa teórica que sostiene la estructura del libro: la necesidad de señalar la heterogeneidad de las formaciones sociales y en su revés, la crítica a la homogeneidad como modo de entender la teoría social que define una excluyente concepción de ciudadanía. En este sentido, a lo largo del libro Pratt teoriza sobre las producciones culturales desde el punto de vista de los que están excluidos del poder o de la normalidad, y así pone en evidencia la complicidad entre las estructuras de poder y las formas de producción del saber. En los fundamentos teóricos que sustentan su análisis, entonces, se halla el concepto de colonialidad planteado por Aníbal Quijano, quien ha señalado que con la Conquista se inició un proceso global que dividió a la población en razas, consagró el eurocentrismo e instauró el control de la subjetividad y del saber.

El segundo capítulo tiene el mismo título que el libro, aunque con una especificación: "Los imaginarios planetarios: a la luz del Gran Televisor Solar" y continúa con la pregunta en torno a cómo se conforman los límites de la otredad. Parte de una anécdota familiar: un almuerzo con su hijo en un comedor vegetariano de la ciudad de Cuzco en el cual se cruza con "Alfa y Omega”, un grupo que surge en el contexto del neoliberalismo expansionista y articula un imaginario planetarizado a través del cual expresa su rechazo al materialismo y la narrativa del desarrollo. La hipótesis 
de Pratt es que estos grupos responden a aspectos descontrolados y contradictorios del proyecto neoliberal, ya que este supone zonas de exclusión en las cuales muchos individuos son "y saben que son" superfluos para el orden global de producción y consumo. En consecuencia, analiza cómo estas zonas de exclusión han sido abordadas por la literatura, por ejemplo, en obras de Diamela Eltit, Mario Bellatin y César Aira. Su lectura le permite señalar cómo el imaginario planetario requiere un concepto de lo humano que está más allá de la llustración y del Capitalismo.

En "Los que se quedan: cuerpos, identidades, espacios" teoriza sobre lo cotidiano (Michel de Certeau, 1979) y la literatura de viajes, aunque aquí en vez de centrarse en los que parten, en el viajero (hombre, blanco) y en su relato, opta por los que se quedan. De este modo, desliza una crítica al advertir que en la imaginación moderna occidental la movilidad es una de las figuras de la libertad y el viaje una de las principales figuras del conocimiento $y$, frente a esta imagen de la movilidad asociada a libertad, la contraimagen es la esclavitud, el exilio, el secuestro y la deportación. Pratt formula una pregunta que resulta estimulante para pensar su corpus, pero también para construir otros alternativos: ¿de qué manera, dentro de una óptica occidental, se vuelve la inmovilidad o el quedarse una figura de libertad en lugar de una figura de encierro? Señala que esas articulaciones contemporáneas no son nuevas, sino que reconfiguran el campo epistemológico colonial e imperial y para demostrarlo se apoya en la teórica quechua-estadounidense Sandy Grande. En el capítulo siguiente, el caso de la devoción y la historia de la virgen de Zapopan en México le sirve para abordar cómo se manifiestan, a finales del siglo XX y principios del XXI, la movilidad, modernidad y ciudadanía. Señala que en la época contemporánea se reactualizan los archivos de viajes de los siglos XVII y XVIII porque resurgen los mismos temas, pero en el presente la atención está puesta en los muertos más que en los vivos: por ejemplo, en las migraciones clandestinas y el sufrimiento o muerte de los migrantes. Mientras que los géneros de los siglos XVII y XVIII eran narrados por los supervivientes y había, por lo tanto, un desenlace feliz; el protagonista de los relatos actuales es, en la mayoría de los casos, el que no logra sobrevivir. Esta movilidad está atravesada por los procesos de descolonización pos Segunda Guerra Mundial, pero también por imperativos y posibilidades generados por los avances tecnológicos, la revolución de las comunicaciones y el neoliberalismo o capitalismo tardío. En esta perspectiva, Pratts analiza de qué modo en un primer momento, desde las metrópolis hegemónicas, se consolida una imagen positiva de la globalización que se patentiza en el uso del concepto de "flujo" para hablar de la movilidad. En Los imaginarios planetarios, desmantela ese concepto para describir que el neoliberalismo no genera pertenencia, colectividad ni futuro, sino que, por el contrario, es excluyente. En sintonía con esta lectura, en el capítulo siguiente propone algunos parámetros para realizar un análisis global y relacional de la modernidad. En primer lugar, presenta un estado de la cuestión acerca de las formas en que la modernidad habla de sí misma en el centro metropolitano, cómo el centro codifica la periferia en los análisis de la modernidad y cómo se ha descrito la modernidad desde las perspectivas de la periferia. Pratt utiliza intencionalmente los términos "centro" y "periferia" para mostrar que el concepto de "globalización", que supuestamente reemplazó esta dicotomía, encubre la persistencia de las funciones del centro, pero sin denominarlo como tal.

En el quinto capítulo, analiza de qué manera las celebraciones del bicentenario de las luchas por la independencia de Hispanoamérica retomaron los archivos e imaginarios de los procesos históricos del siglo XVIII y principios de XIX y, en ese sentido, propone pensar la independencia como un ejercicio de "futurología", ya que observa la persistencia del uso de futuros para hablar de independencia. Frente a la construcción del relato nacional, Pratt formula el experimento inverso: imagina la independencia como la proyección hacia un futuro desconocido, incognoscible e impredecible $y$, desde este planteo, la independencia no designa un proceso sino una idea que se materializa a través de la improvisación y el riesgo.

En "El tráfico de significado: traducción, contagio, infiltración" delimita algunos problemas derivados de la idea de "traducción cultural", que usa como metáfora para describir este tráfico en escenarios de distancia o diferenciación lingüística y cultural. Examina un documento elaborado por José Antonio de Areche desde la Corte Real de Lima (1781) en el cual se especifica la respuesta española a una revuelta indígena y se propone una campaña de destrucción cultural; este documento le permite revisar la creación de significados interculturales que luego repiensa a partir de las ideas sobre traducción de Eliot Weinberger y Clifford Geertz. Los conflictos lingüísticos constituyen también el eje sobre el que se articula el capítulo que cierra la primera parte, pero, en este último caso, parte de situaciones experienciales, tanto de su faceta materna como docente, para luego releer un texto como el de Felipe Guamán Poma de Ayala y desarrollar la teoría de las zonas de contacto.

La segunda parte -Figura-rastrea la presencia de los procesos históricos en producciones culturales de 
diversos momentos del siglo XIX y XX. En el primer capítulo, Pratt analiza el film También la lluvia (2010) de Icíar Bollaín para demostrar que la articulación del concepto de "colonialidad del poder" es válido para pensar la actualidad de los conflictos latinoamericanos. Al ubicar el relato en la Guerra del Agua de Cochabamba en la primavera del año 2000, la película amalgama con maestría el pasado y el presente de las jerarquías, relaciones e instituciones coloniales en nuestro continente.

En el segundo capítulo toma el concepto de Carol Pateman en The Sexual Contract (1987) con el objetivo de revisar el tema de la violencia y delimitar una metodología atenta a considerar de qué maneras este tema se estructura por el género. Parte de La virgen de los sicarios (1994) de Fernando Vallejo para ofrecer observaciones sobre la configuración de género y de sexo que acompaña el ambiente de violencia urbana en otras cuatro novelas de la década de los noventa: Plata quemada (1997) de Ricardo Piglia, Tú, la oscuridad (1995) de Mayra Montero, Salón de belleza (1994) de Mario Bellatin y Los vigilantes (1994) de Diamela Eltit. La producción de la escritora chilena vuelve a ser objeto de análisis de su siguiente ensayo, pero esta vez se centra en El Padre Mío (1989), texto que analiza junto a otros que desbarataron la cultura del miedo en Chile. Frente al monólogo abstracto, esencialista y evasivo dictatorial, Pratt considera que el testimonio se constituyó como contradiscurso porque reafirmó la experiencia del cuerpo.

El cuarto capítulo toma como punto de partida la metáfora que elabora Jesús Martín Barbero, “mapa nocturno", para imaginar una cartografía de las mujeres de América Latina que han escrito y/o escriben y visibilizar lo que llama "mapa diurno" que da cuenta de la violencia y crueldad del sistema con los cuerpos de las mujeres (Ciudad Juárez, como ejemplo testigo). En este recorrido recupera distintas anécdotas que ponen en evidencia que las escritoras, artistas (y también la crítica) latinoamericanas han tenido que luchar contra instituciones androcéntricas y misóginas que subordinan, eliminan o devalúan sus producciones. El capítulo siguiente se centra en una figura medular de la ideología nacional mexicana: la Malinche. Primero realiza un estado de la cuestión sobre las lecturas de esta figura en el campo cultural mexicano y luego se revisa los años setenta en Estados Unidos cuando fue retomada y resemantizada por poetas chicanas para asumir sus propias luchas de género y etnicidad, en lo que se conoce como etnonacionalismo.

En el sexto capítulo nuevamente se centra en una escritora, la mexicana Nellie Campobello, cuya historia le permite poner en primer plano no solo el ocultamiento al que el campo cultural sometió su producción y vincular este hecho con los vericuetos que ha tenido el secuestro y ocultamiento de su cuerpo. Pratt analiza dos obras narrativas -Cartucho (1931) y Las manos de mamá (1937)- para trazar el perfil de la Revolución mexicana (cuya narrativa queda, en general, en mano de escritores) y establecer vínculos con la práctica coreográfica que también desarrolló esta artista. Destaca el carácter experimental de su obra y el desarrollo de una óptica feminocéntrica sobre el estado de guerra. Pratt es categórica al señalar que el experimentalismo narrativo de Las manos de mamá permite ubicar esta obra como precursora (no reconocida) de Pedro Páramo de Juan Rulfo, Al filo del agua de Agustín Yáñez, La región más transparente de Carlos Fuentes y Recuerdos del porvenir de Elena Garro.

En “'No me interrumpas': mujer, literatura, y nación 180o-1920", analiza lo que llama "ensayos de género" escritos por mujeres latinoamericanas y señala las dificultades que le ocasionó construir el corpus, ya que el ensayo latinoamericano es fuertemente androcéntrico. Analiza producciones de Gertrudis Gómez de Avellaneda, Juana Manso, Clorinda Matto de Turner, Alicia Moreau de Justo, Victoria Ocampo, Rosario Castellanos, por nombrar algunos ejemplos. La cita del título la extrae de un ensayo en el que Victoria Ocampo expresa la preferencia de los hombres a monologar en vez de dialogar con las mujeres. Estas palabras le sirven a Pratt para señalar que la historia de la literatura ha interpretado al ensayo como uno de esos monólogos masculinos en los que se ha desalentado o prohibido que las mujeres intervengan. Aborda su corpus como respuesta a la autoridad intelectual masculina, pero también propone el juego inverso, es decir, leer el ensayo de identidad criolla como respuesta a las demandas de los grupos marginados por una plena inclusión en la sociedad.

En el último capítulo, identifica la configuración de "silencios fundacionales" (en diálogo con los discursos fundacionales) que posibilitan la narrativa emancipatoria del siglo XIX. Para ella, dos de estos silencios son el carácter parcial de la descolonización americana y el silencio sobre el papel de la subordinación de la mujer en la constitución de la nación-Estado. En particular, le interesa demostrar cómo estos dos silencios determinaron la recepción de la figura literaria de Gertrudis Gómez de Avellaneda y la relación que mantuvo con José María Heredia.

Sin duda, resulta estimulante la lectura de ensayos críticos que colocan el texto bajo sospecha para llegar a lo no explícito y sacar a la luz los puntos de tensión 
que las textualidades no resuelven. Este ejercicio crítico ya lo desplegó en sus producciones anteriores, y aquí también lo pone en movimiento para leer un corpus heterogéneo que permite revisar la configuración del imaginario planetario que, en la actualidad, ya pasadas dos décadas del siglo XXI, se hace cada vez más evidente. Si los proyectos imperiales se asentaron sobre la exclusión y la violencia (de género, de raza, de clase) como norma, también es posible leer a contrapelo las prácticas de resistencia que se han tejido. Para los latinoamericanos del siglo XXI, la crisis planetaria (o global, como quieran Ilamarla) constituye el cristal por el que miramos nuestra cotidianeidad, y por eso, este libro de Mary Louise Pratt es un aporte indispensable para (re)pensar qué contratos sociales nos han impuesto y cuáles necesitamos (re)fundar o transgredir. 